stroyed are so great that the conversion of all the effete hæmoglobin into bilirubin cannot be effected, though the amount is undoubtedly increased, so that the undestroyed hæmoglobin appears in the urine. In this case there is also an excess of urea and of urinary pigment, together with the presence of albumen in the urine.

These gradations of hremolytic action may be thus expressed :

\begin{tabular}{|c|c|c|}
\hline $\begin{array}{c}\text { Ordinary } \\
\text { hremolysis. }\end{array}$ & $\begin{array}{c}\text { Urinary pigment, } \\
\text { urea. }\end{array}$ & Normal urine. \\
\hline $\begin{array}{l}\text { Active } \\
\text { amolysis. }\end{array}$ & $\begin{array}{c}\text { Increase of urinary } \\
\text { pigment, increase of } \\
\text { urea. }\end{array}$ & $\begin{array}{l}\text { Urine of } \\
\text { digestion. }\end{array}$ \\
\hline $\begin{array}{l}\text { Increased } \\
\text { hromolysis. }\end{array}$ & $\begin{array}{c}\text { Increase of urinary } \\
\text { pigment, appearance } \\
\text { of bile pigment, } \\
\text { increase of urea, } \\
\text { albumen in urine. }\end{array}$ & $\begin{array}{l}\text { Functional } \\
\text { albuminuria. }\end{array}$ \\
\hline $\begin{array}{l}\text { Extraordinary } \\
\text { hamolysis. }\end{array}$ & $\begin{array}{c}\text { Hæmoglobin in urine, } \\
\text { increase of urinary and } \\
\text { bile pigment, increase } \\
\text { of urea, albumen in } \\
\text { urine. }\end{array}$ & Hæmoglobinur \\
\hline
\end{tabular}

With regard to the pathological conditions that induce this increased and extraordinary hamolysis in functional albuminuria and hemoglobinuria we are, still in the dark, though it is probable they are of the same character, but differing in intensity. If asked to formulate an hypothesis, I would say that in both the essence of the disease consists in an increased irritability of the vaso-motor reflex centre, which causes increased bæmolysis in the liver; but, in addition to this, there is the formation, probably owing to disorder of the blood-forming organs, of corpuscles unable to withstand unusual disintegrating influences. The fact that individuals suffering from functional albuminuria, or hæmoglobinuria, have generally some taint, hereditary or acquired, such as gout, rheumatism, syphilis or malaria, accounts, no doubt, for the disorder of the blood-forming organs, and also possibly for the instability of the vaso-motor reflex centre. With regard to the treatment of the two conditions, the same may be pursued in both. The diet should be light and chiefly non-nitrogenous, care being taken not to prolong the intervals between meals too long, or to allow too much food to be taken at any one time, since from the experiments of Nicolaides it has been shown that the hymolytic action of the liver is increased during active digestion or by the ingestion of too much food; whilst too much nitrogenous food undoubtedly increases the metabolic activity of the liver. Quinine and iron are essential, but when given with arsenic the best results are obtained. Arsenic appears to have the power of diminishing the hæmolytic action of the liver, as well as strengthening the resisting power of the red blood-corpuscles.

Queen Anne-street, $W$.

\section{THE TREATMENT OF INTUSSUSCEPTION BY INFLATION AND MASSAGE.}

BY W. B. CHEADLE, M.D., F.R.C.P.,

SEXIOR PIYSICYAN TO TELE HOSPTTAL FOR SICK CHILDREN, GREAT ORIONDSTREXT, AYD PAYSICIAN TO ST. MIARY'S HOSPITAY.

IN these days of the apotheosis of abdominal surgery, instances of the cure of intussusception by inflation and manipulation of the abdomen deserve to be recorded as a useful reminder of the value and efficacy of the milder metnod. Three consecutive cases have been successfully treated in this way at the Hospital for Sick Children during the past eighteen months - two under my own care, and a third under that of my colleague, Dr. Barlow.

The first case (for the history of which I am chiefly indebted to the registrar, Dr. Chaffey) is that of Ernest Caged five months, admitted July 12 th, 1884, with constipation, frequent vomiting, and passage of blood from the rectum. The doctor who had been called in to see the child in the first instance diagnosed intussusception, and advised that he should be taken to the hospital without delay. The further history elicited from the mother was to the effect that the infant had been healthy previously, except for slight bronchitis and occasional constipation. One of these attacks of constipation commenced on the 4 th (eight dajs before); and on the 7 th, the bowels not having been open for three clays, the mother administered a dose of "white magnesia." The following day (the sti) the cluild had a natural stool. On the $9 t h$ half a Steedman's powder was administered, followed by two actions on the 10th. The other half of the powder was given, but the bowels were not moved again. On the next afternoon (the 11th-i.e., the day before admission) the child kicked and screamed so much after being put to the breast, as if he had pain in the abdomen, that the mother applied hot flannels. These seemed to give relief, and he slept for some time. In the evening, however, he became restless, and about midnight began to vomit, which he continued to do repeatedly. For the last hour the vomit was green and watery. At 5 A.M. Q thin bloody discharge began to be passed from the bowel, and this recurred three or four times. The infant was seen by me almost immediately after it was admitted. It was fat, but somewhat pale and flabby; it did not appear distressed, although it had frequent oiccough. The temperature was subnormal. The abdomen was not greatly distended, but more resisting to palpation than usual, and the handling evidently caused discomfort. Passing from side to side, about an inch above the level of the umbilicus, an elongated sausage-like tumour could be distinctly felt. It extended into the left, flank, and was there lost. It could not be felt in the right flank, although it commenced to the right of the middle line. It was smooth, could be moved upwards and downwards a little, and did not appear to be very tender. Examination by the rectum showed it to be empty. There were no fæces. The withdrawal of the finger was followed by the discharge of thin bloody fluid. An injection of warm water was at once given with an ordinary Higginson's syringe, but not more than two syringefuls could be passed in; it was forcibly returned at once, in spite of all attempts to prevent it. Injection of air was accordingly substituted; four syringefuls were introduced, and kept in by pressing the folds of the buttocks and the skin of the anus closely round the base of the nozzle of the syringe. At the same time the abdomen was kneaded externally. It was found that at least three persons were required to carry on these operations satisfactorily - viz, one to work the syringe, one to compress the anus and prevent the escape of air, and a third to manipulate the abdomen. After this process had been continued for some minutes the tumour was found to hare disappeared. On careful re-examination a quarter of an hour later no tumour could be detected. When, however, the child was again examined by the house-surgeon, Dr. Thomson, some hours afterwards, a firm, sausage-like tumour was again distinctly felt in the right hypcchondrium. Digital examination again showed the rectum absolutely empty except of sanious fluid, which followed the withdrawal of the finger as before. The injection of air and massage were accordingly repeated by Dr. Thomson under chloroform, which greatly facilitated the proper carrying out of the operation. This time ten syringefuls of air were injected, when the bowel was felt to become hyper-distended in the left flank. After a few minutes the air was allowed to escape, and it was then found that the characteristic tumour had again disappeared, although it was thought that the colon could be felt more rioid and thickened than normal. This would probably be its condition from the swelling of congestion. About four hours later the child passed a natural motion, and again took the breast readily; the bowels continued to act regularly, the tumour did not return, and after a few days the little patient was discharged well.

The second case (for the notes of which I am also largely indebted to the registrar) was that of James $S$ - aged five years and a half, admitted May 27 th, 1885 . On the 20 th he had been suddenly seized with violent pain in the lower part of the abdomen, which recurred constantly day and night, with frequent vomiting. Slime and blood passed from the bowels for the first two days, but no fiecal matter. Subsequently, the bowels did not act until the 26th, when a little hard fæcai matter passed. After this the vomiting and pain were much less. A similar attack was said to have occurred three years ago. The present one was attributed to getting wet on walking home from a friend's house, where he had supper. On this occasion a fish-bone stuck in his throat, and the father gave him some ale to wash it down. These events happened on the $19 \mathrm{th}$, the night before the pain and vomiting commenced. The patient being admitted late in the day, and there being no urgent symptoms, he was not minutely examined by the 
Gouse-physician until the evening. In the meantime he had once passed some blood and mucus, and afterwards blood alone. Examination showed the abdomen unduly distended, and a large sausage-like tumour could be felt, extending from the lower epigastric region to the left hypochondrium. It was almost identical in character and situation with that in the previous case. The rectum contained only some bloody fluid. Dr. Thomson at once communicated with me. On my arrival, finding that there was no doubt about the existence of intussusception, inflation was carried out as before by Higginson's syringe, under chloroform, and accompanied by massage. As the air began fully to distend the intestine, the tumour was felt to pass gradually from the left hypochondrium to the right flank, and finally disappear. After a few minutes the air was allowed to escape. No tumour could be found, but, to make assurance doubly sure, the inflation and massage were repeated, and continued for a longer period. At the close of this the abdomen was again examined. The only sign of the tumour which could be detected was some rigidity of the bowel in the region of the cæcum. This remained, and was followed by pain and tenderness there. Subsequently there was increased tympanites and general tenderness, with diarrhœa, but no marked rise of temperature. These symptoms abated very gradually and with many fluctuations, the resistance and tension in the right iliac fossa and the diarrhoea not finally subsiding for some weeks. At the beginning of August the boy went out well.

The third case, under the care of my colleague, Dr. Barlow, was closely analogous to the first case in the conditions found and in the result achieved. For the details of it I am indebted to the kindness of Dr. Swift, housephysician to the hospital at the time, who had the conduct of the case in the emergency. Amy McF-_- aged six months, was admitted on June 7 th, 1885 , at 11.30 P.M. She thad been for some time an out-patient on account of diarrhœe, and for the previous four days she had not been so well, having been without medicine. At 1 P.Mr. on the day of admission-i.e., about ten hours before-she had suddenly begun to scream violently every few seconds, kicking and wriggling about, and romiting frequently. She passed some bright-red blood and mucus, but no fæces. The screaming and vomiting continued during the whole of the afternoon .and evening, until she was brought to the hospital. She was a healthy-looking child, but evidently in great pain, screaming and kicking continually. The right side of the abdomen felt empty, especially in the region of the cæcum; while on the left side there was a tumour, seemingly about two inches thick and some three inches and a half long, lying transversely from just above the umbilicus to the left hypochondrium, and there curving slightly downwards. It was freely movable and firm; no impression could be made upon it. Intussusception was diagnosed, and the child was forthwith placed fully under the influence of chloroform. The above position of the tumour was then verified. Nothing could be felt in the rectum, but a little blood escaped. The bowel was inflated, as in the previous cases, with a Higginson's syringe, and the abdomen kneaded by the hand. The tumour could be felt receding as inflation proceeded, until the abdomen was fully distended. When the air was allowed to escape, a slight thickening could still be felt in the region of the tumour. Dr. Swift accordingly again inflated the bowel, and this time the whole course of the large intestine could be clearly seen. On the air escaping once more, no tumour, thickening, or resistance could be found anywhere. A drop of laudanum was administered after the child had regained consciousness, but as she continued to scream chloroform was again administered lest the excitement should cause return of the intussusception; four hours' sleep followed. The next day the child was well, no thickening or tumour could be detected, and no further trouble followed.

The point chiefly worthy of remark in the first case is the return of the tumour after its disappearance on the first inflation. The explanation seems to be that the intussuscepwas only partially overcome in the first attempt. This explanation is rendered probable by the fact that ten syringefuls of air were introduced on the second occasion, instead of only four, as in the first, the bowel unfolding more easily under the distending pressure, and admitting at once a larger rolume of air. If the tumour had merely been displaced by the first operation, it would have quickly returned when the pressure was relieved by the escape of the introdused air, and some trace of it would have been found at the examination a quarter of an hour later. The use of chloroform probably greatly aided in the success of the second inflation by preventing the resistant contraction of the abdominal muscles.

In the second case, the immediate and complete reduction of the invagination at the first attempt, and its failure to return, are deserving of note; and also the prolonged typhlocolitis which followed, partly due possibly to the more prolonged distension and massage, and partly to the greater congestion of the gut from longer strangulation. The history of pain and vomiting, probably indicating partial invagination, extended in this case over a woek, in the others only twenty-four hours and ten hours and a half respectively. The successful use of inflation in an instance where the symptoms of intussusception had existed so long is very noteworthy. From the history of a previous attack of pain and vomiting, it seems probable that the boy had suffered from typhlitis before, and that the present intussusception had its origin in slight typhlitis. The valve orifice being thus rendered more rigid, the involution of the large bowel by the more active peristalsis of the small intestine would be greatly favoured.

The third case corresponds very closely with the first. The intussusception was recent; it was completely reduced, and no after consequences of any kind followed.

\section{THE CONNEXION BETWEEN PULMONARY PHTHISIS AND OVARIAN DISEASE.}

BY BEDFORD FENWICK, M.D., M.R.C.P.,

ASSISTANT-PHXSIOTAN TO THE CITY OF LONDOY HOSPITAT FOR DISEASES OF THE CHEST, VICTORIA PARK, AYD TO THE HOSPITAL FOR

WOMEN, SOHO-SQUARE.

(Concluded from page $71 \%$.)

I HAVE examined with some care the literature of the subject for the last half-century, and have failed to find that any observer has hitherto suggested or proved any family predisposition to any special disease in these cases. And this appears the more strange, not only when the large number of great clinicists and writers who have discussed the matter is remembered, but especially when the pathology of the disease is thoughtfully considered. For it is, I take it, generally accepted that most, if not all, the various forms of intra-ovarian cysts originate in a degeneration of one or more Graafian follicles. ${ }^{1}$ We recognise that cancer in the parent may cause a similar disease in the offspring, that phthisis descends from generation to generation, that gout and many other diseases are distinctly hereditary. And phthisis, I venture to believe, really passes from the father or mother to the children, not because the spermatozoa or the ovum contains a baby bacillus, but because it bears in some wonderful way an impressed general tendency to early degenerative changes, plus, perhaps, a local tendency to pulmonary disease. Other hereditary diseases show their transmitted types in the later days of life; phthisis in its early effects. And so it certainly appears to me that a family tendency to early degenerative changes might, prima facie, be suspected in a patient, who develops the slow degeneration of the Graafian follicle, which culminates in the fully formed ovarian cyst. But, as I have said, I have failed to find anything relating to this matter in modern medical literature, and I have therefore had to content myself with a smaller number of facts culled from fewer sources than I could have wished. 1 think, however, that they will be sufficient to show the probability at least of what I desire chiefly to call attention to-viz., the theory that ovarian cystic disease arises in many cases becantse tile patient has an hereditary tendency to degenerative changes, or, in other words, belongs to a phthisical family.

My facts, then, consist, firstly, of all the cases of ovariotomy performed or of ovarian cyst found post mortem at, the Hospital for Women from the beginning of 1882 up to the present time- 148 in number,-and of two cases occurring in intimate friends of my own, so as to make a series of 150 in all ; secondly, of two family charts showing the cause of each death ; and, thirdly, some isolated cases from

1 Wilson Fox: Royal Medicn-Chirurgical Society's Transactions, June, leit. Harris and Doran: Journal of Anatomy and Physiology, 